\title{
A randomized controlled trial of an intervention for infants' behavioral sleep problems
}

Wendy A. Hall ${ }^{*}$, Eileen Hutton ${ }^{2}$, Rollin F. Brant ${ }^{3}$, Jean Paul Collet ${ }^{4}$, Kathy Gregg ${ }^{5}$, Roy Saunders ${ }^{6}$, Osman Ipsiroglu' Amiram Gafni ${ }^{8}$, Kathy Triolet ${ }^{9}$, Lillian Tse ${ }^{10}$, Radhika Bhagat ${ }^{11}$ and Joanne Wooldridge ${ }^{12}$

\begin{abstract}
Background: Infant behavioral sleep problems are common, with potential negative consequences. We conducted a randomized controlled trial to assess effects of a sleep intervention comprising a two-hour group teaching session and four support calls over 2 weeks. Our primary outcomes were reduced numbers of nightly wakes or parent report of sleep problem severity. Secondary outcomes included improvement in parental depression, fatigue, sleep, and parent cognitions about infant sleep.

Methods: Two hundred thirty five families of six-to-eight month-old infants were randomly allocated to intervention $(n=117)$ or to control teaching sessions $(n=118)$ where parents received instruction on infant safety. Outcome measures were observed at baseline and at 6 weeks post intervention. Nightly observation was based on actigraphy and sleep diaries over six days. Secondary outcomes were derived from the Multidimensional Assessment of Fatigue Scale, Center for Epidemiologic Studies Depression Measure, Pittsburgh Sleep Quality Index, and Maternal (parental) Cognitions about Infant Sleep Questionnaire.

Results: One hundred eight intervention and 107 control families provided six-week follow-up information with complete actigraphy data for 96 in each group: $96.9 \%$ of intervention and $97.9 \%$ of control infants had an average of 2 or more nightly wakes, a risk difference of $-0.2 \%$ (95 \% Cl: $-1.32,0.91) .4 \%$ of intervention and $14 \%$ of control infants had parent-assessed severe sleep problems: relative risk 0.3 , a risk difference of $-10 \%$ (Cl: $0.11,0.84-16.8$ to -2.2 ). Relative to controls, intervention parents reported improved baseline-adjusted parental depression (Cl: -3.7 to -0.4$)$, fatigue ( $\mathrm{Cl}:-5.74$ to -1.68$)$, sleep quality ( $\mathrm{Cl}:-1.5$ to -0.2$)$, and sleep cognitions: doubts (Cl: -2.0 to -0.6$)$, feeding (Cl: -2.1 to -0.7$)$, anger (Cl: -1.8 to -0.4$)$ and setting limits (Cl: -3.5 to -1.5$)$.
\end{abstract}

Conclusions: The intervention improved caregivers' assessments of infant sleep problem severity and parental depression, fatigue, sleep, and sleep cognitions compared with controls.

Trial registration: ISRCTN42169337, NCT00877162

Keywords: Randomized controlled trial, Multi-component intervention, Behavioral sleep problems, Infants, Actigraphy, Diaries, Parents

\footnotetext{
* Correspondence: wendy.hall@ubc.ca

'University of British Columbia School of Nursing, T 201, 2211 Wesbrook Mall, Vancouver, BC V6T 2B5, Canada

Full list of author information is available at the end of the article
} 


\section{Background}

Behavioral sleep problems (BSP) affect 20 to $30 \%$ of infants and often persist from infancy to later childhood $[1,2]$. Predominant problems identified by parents are infants' difficulties in falling asleep and staying asleep [2], which create fragmented sleep and/or short sleep duration. Adequate sleep duration is associated with increased infant adaptability and rhythmicity [3], while night waking with crying has been associated with greater stress reactivity, for example, during inoculations [4]. Young children's BSPs have been linked to hyperactivity, and cognitive, emotional, and behavioral difficulties, after controlling for maternal depressive symptoms [5-9]. Infants' BSPs have been associated with maternal depressive symptoms, serious psychological distress, poor general health, and feelings of incompetence [10-12]. Fathers, although rarely studied, have reported poorer general health and more psychological stress when their infants have BSPs [11].

A review of over 50 published treatment studies for children's BSPs indicated behavioral interventions were efficacious, with over $80 \%$ of children treated demonstrating clinically significant improvement that was maintained for 3 to 6 months [13]. Reviewers recommended future studies test group interventions and incorporate actigraphy as an objective sleep measure, measures of parental depression, and combined objective and subjective (parental diary) sleep measures [13]. Our before-after design pilot study of a cognitive-behavioral group intervention (CBGI) for seven groups of five parents $(n=35)$ with 6-to-12-month-olds experiencing BSPs demonstrated significantly reduced numbers of night wakes and longer night sleep time, by actigraphy, post intervention [14], as well as significantly improved parental mood, sleep quality, fatigue, and cognitions about infant sleep [15]. The CBGI involved a two-hour teaching session and two weeks of telephone support. Parents in that study reported that participating in a group teaching session with other parents whose children had sleep problems 'normalized' what they were experiencing and helped them regard their children's sleep problems as common and amenable to change. Being part of the group and receiving telephone support calls increased their confidence to manage infant sleep [16].

In Canada, public health units are located in communities and deliver population-based programs and services that protect and promote Canadian's health and focus on primary prevention [17]. Services vary by province and health authorities. In Vancouver, British Columbia, public health nurses have brief contact with healthy infants at birth, with no further formal contact unless families attend immunization clinics or postnatal drop-ins. Postnatal drop-ins offer families information about children's nutrition and safety, adjusting to parenthood, and sleep [18].
Sleep sessions have provided general information about infant sleep and overviews of potential approaches to managing infant sleep. Our randomized controlled trial aimed to determine the efficacy of a cognitive-behavioral group intervention, offered through public health nurses. Our hypotheses were: fewer intervention group infants would have $\geq 2$ night wakes or fewer intervention group parents would identify infants as having severe sleep problems at 6 weeks post-teaching session than control group parents. Secondary outcomes, at 6 weeks post-teaching session, were that parental mood, sleep quality, fatigue, and cognitions about infant sleep would improve significantly more in the intervention group and intervention group infants would have significantly longer longest sleep periods (actigraphy) and significantly fewer night wakes (actigraphy and sleep diary) than control group infants.

\section{Methods}

\section{Ethics statement}

The University of British Columbia (H09-00757) and Vancouver Coastal Health (\#CS09-076) Research Ethics Boards approved the trial. Informed consent was provided by all participants, after obtaining written and oral information about the study. The consent form included the statement that the parents consented to their infant's participation in the study. A data and safety monitoring board met annually to monitor adverse events. None occurred. No changes were made to the trial after commencement. The trial was registered on the following sites: ISRCTN, 42169337, url: http://www.isrctn.com/ NCT00877162, url: https://clinicaltrials.gov/.

\section{Participants and procedures}

Posters, media announcements, online classifieds (Kijiji and Craigslist), and Facebook were used to disseminate information to families in the Greater Vancouver area about the trial. Posters were placed in coffee shops, libraries, community centres, and public health units. Interested families contacted the study coordinator to ask questions and be screened for inclusion. Families were told that we were testing an intervention to see whether it would improve infants' BSP and that they would be assigned to receive the intervention or a control session on infant safety.

Eligible families were biological or adoptive, able to read and speak English, had access to a telephone, and constituted a single or two-parent family. Both parents in a two-parent family had to commit to participation in the study. Eligible infants had no identified health problems, were between corrected ages of five-point-five and eight months at recruitment, and were either sex. The study coordinator used a list of questions to determine whether infants met the inclusion criterion of demonstrating moderate BSP, as defined by the American 
Association of Sleep Medicine clinical Classification of Sleep Onset Association disorder (waking two or more times per night at least five nights per week) [19]. Parents who reported depression or sleep problem diagnoses or treatment, worked permanent night shifts, or lived outside the study catchment area (Greater Vancouver) were excluded. We excluded infants with organic causes of sleep disruption, developmental disability, or chronic neurological or respiratory conditions.

At baseline, research assistants delivered questionnaires (demographic, depression, sleep quality, sleep cognitions, and fatigue measures), actigraphs, and study-designed sleep diaries to families. Research assistants (blinded to group assignment) demonstrated how to apply actigraphs and complete the record of actigraph application and removal and sleep diaries. They also provided an information sheet that explained when to begin and end collecting actigraphic and diary data simultaneously. The research assistants left the questionnaires with the parents for self-administration. Baseline actigraphic and diary measurements occurred over 6 days. The first families were enrolled in September 2009; the final outcome assessment was completed in September 2011.

After the study coordinator enrolled families and research assistants obtained consent and baseline measurements, families were randomly allocated in sequential blocks of 10 to intervention (sleep) and control groups (safety) at each site (Fig. 1). The sequential blocks were to ensure that families were equally distributed by group designation and geographic area (4 health unit sites). A data manager used a computerized secure software platform to randomly assign families to groups.

Families attended a teaching session at one of 4 health units and received follow-up phone calls from the nurse who taught the session. Families from outside the health unit geographical boundaries attended a teaching session at the health unit closest to their geographical location. The same follow-up measurements (over 6 days) were conducted 6 weeks after the teaching intervention. A total of 25 intervention and control sessions occurred at

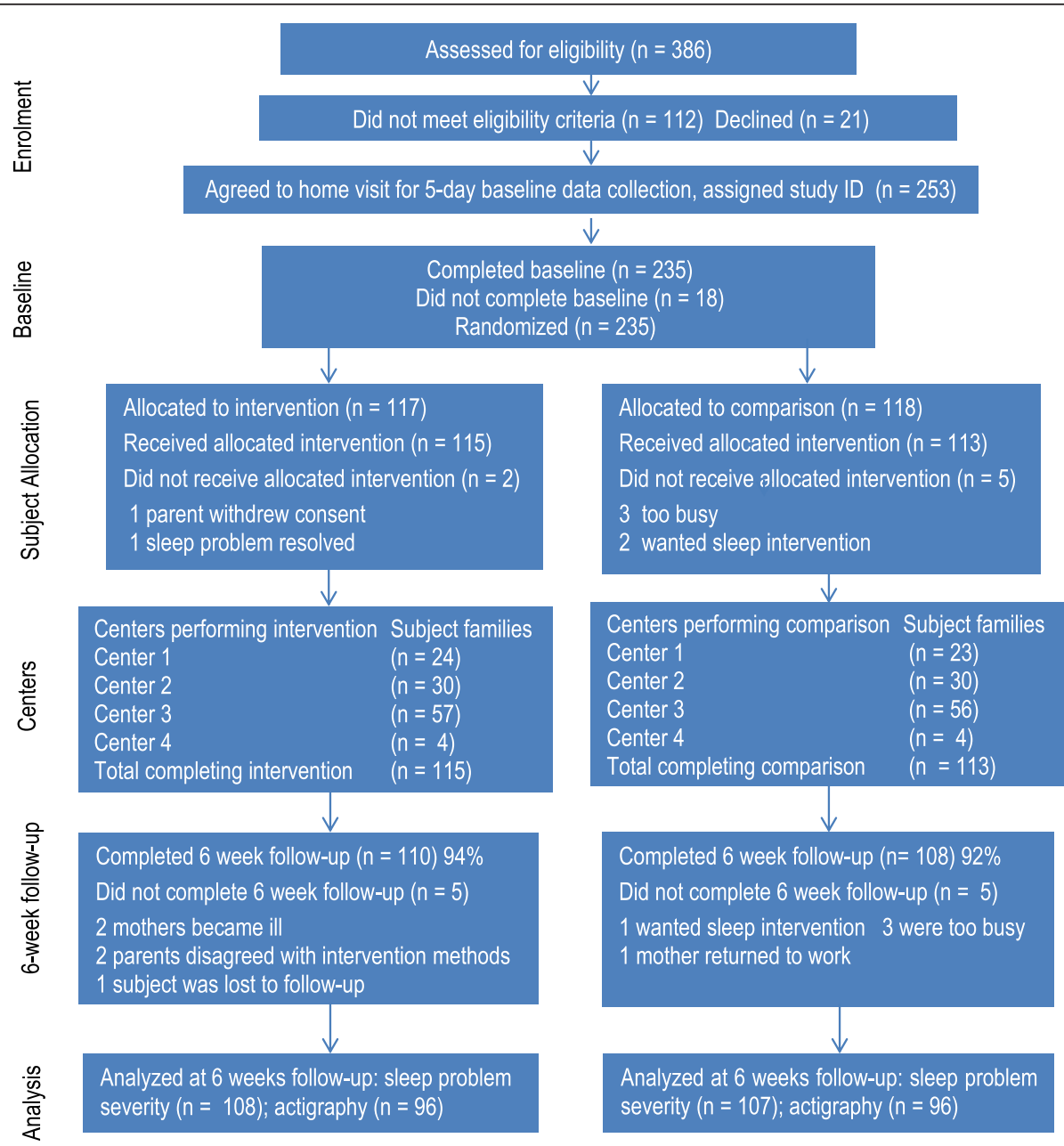

Fig. 1 Participant Flowchart (CONSORT) 
roughly five-week intervals. After six-week data collection, the sleep group received the infant safety information and the safety group received the infant sleep information. We provided the safety group with infant sleep information because the literature indicates infants' BSPs have negative outcomes for parents [10-12] and infants [4] and we regarded it as unethical to withhold a potentially useful intervention in the absence of any standard accessible treatment for infant BSP.

\section{Intervention}

Our intervention aimed to improve a BSP at an age when infants are developmentally capable of sustaining a long self-regulated sleep period for, on average, $10 \mathrm{~h}$ [20]. We sought to change families' cognitions and behaviors to promote infant self-soothing and targeted our intervention to both parents because both have affected infant sleep [21]. Parental cognitions are defined as beliefs, expectations, and interpretations of children's sleep behavior which are viewed as influencing parent-infant interactions and infant sleep patterns [22, 23]. Because public health nurses frequently encounter families experiencing infant BSP we trained them to deliver the sleep intervention. Nurses also delivered the safety control sessions. The principal investigator created the materials for the teaching sessions and phone calls. Total treatment duration was 3 weeks: one 2 -h teaching session followed by bi-weekly telephone calls for 2 weeks. The nurses who delivered the teaching sessions called the parent leading the intervention/control twice a week for 2 weeks to reinforce concepts and provide support. The intervention and control groups were asked the same questions during the telephone calls: How were parents managing; what strategies were they using; what were the effects of their strategies on their infants and the parents; and what, if any, difficulties were they experiencing?

\section{Sleep intervention}

Groups of families received information about normal infant sleep, effects of inadequate sleep for infants and parents, setting limits around infant sleep, the importance of daytime and sleep routines, and negative sleep associations (Table 1). The intervention introduced behaviors that families could use to promote infant selfsoothing, in particular, controlled comforting, with two to $10 \mathrm{~min}$ taken to console the infant and then leaving the room for increments of two minutes up to $10 \mathrm{~min}$ intervals [24]. Families observed a recording of an infant in light and deep sleep (so they could see an infant vocalizing and opening her eyes while asleep) and an interview with parents living with a child with a sleep problem. The video was intended to point to longer term sleep problems when interventions were not initiated in infancy. Families also received handouts of the scripted
Table 1 Topics addressed during teaching sessions

Information about infants' patterns (cognitions)

- Infants have developmental shifts

- Infant feeding requirements at night

- Sleep-wake-feed-play and usual sleep patterns and typical sleep progression

- Infant behaviors associated with sleep types and tiredness cues

Negative Sleep Associations (cognitions)

- Movement to sleep

- Feeding to sleep

- Putting an infant to bed asleep

- Reactive co-sleeping

Unrealistic expectations about sleep (cognitions)

- Less napping and late bedtimes will promote night sleep

- Nap and bedtimes do not matter

- Parents' approaches can differ

Effects of sleep loss on infants and parents (cognitions)

- Associations between behavioral sleep problems and infant growth and development

- Associations between sleep disturbance, parental mood, confidence, and problem-solving

Strategies to Reduce Night Waking (behaviors)

- Daytime, bedtime, and naptime routines

- Minimal stimulation before bed

- Feeding 20 min prior to settling

- Controlled comforting with periodic checking

- Avoid reactive co-sleeping

power point presentation, weekly sleep-wake-feed-play charts (routines), and controlled comforting charts. Charts enabled them to track their use of techniques and any changes in their infants' sleep.

\section{Safety control}

Groups of families learned about infant safety risks, e.g., shaken baby syndrome, choking, falls, sleep positioning, motor vehicle travel, pacifiers, suffocation, strangulation, poisoning, and burns, as well as factors influencing risks and strategies for prevention. Co-sleeping as a risk to infant safety was not discussed. Families received a handout of the scripted power point presentation, which included a safety checklist. Nurses answered questions that were raised during the teaching session, e.g., recalls for cribs or infant car seats.

\section{Training and intervention fidelity}

Ten public health nurses, with five or more years of experience, and three registered nurses, with two or more years of experience in community settings, were separately trained during eight hour sessions for the sleep intervention (Table 2) and safety control. Role plays for delivering 
Table 2 Training program for sleep intervention nurses

- Circadian rhythms \& sleep cycle characteristics
- Normal sleep amount \& patterns for 6-to-12 month-olds
- Developmental shifts in infant sleep and unrealistic parental
expectations
- Effects of sleep fragmentation \& short cycles
- Routines daytime \& pre-sleep
- Negative sleep associations
- Effects of sleep problems on infants
- Effects of sleep problems on parents
- Trials and reviews of behavioral sleep interventions
- Strategies to reduce night waking
- Screening infants for conditions requiring medical referral
Skills
- Screening infants for conditions requiring medical referral

the teaching session and follow-up telephone calls were included. Nurses received training manuals, documents with frequently asked questions and answers about sleep and safety, standard scripted formats for the teaching sessions and follow-up calls, and a PowerPoint Module. Public health nurses received videotaped materials. Ad hoc calls to participants by nurses were prohibited.

Nurses video-recorded their teaching sessions and audio-recorded their follow-up calls for review. The principal investigator reviewed $100 \%$ of the initial training sessions and follow-up calls to provide support and reinforce standardization. Thereafter, the principal investigator randomly reviewed $50 \%$ of videos and $10 \%$ of the follow-up call recordings. In $90 \%$ of teaching sessions and $80 \%$ of calls, nurses followed protocols. The principal investigator worked with nurses omitting prescribed behaviors to incorporate them. The information from the phone calls is not included in this report.

\section{Outcome measures}

Our primary outcome was a composite measure of significant sleep disturbance consisting of either parent reporting a severe sleep problem or mean actigraphic wakes of $\geq 2$ per night averaged over 5 nights. Evidence that the intervention was successful would be significantly smaller proportions of parents reporting severe infant sleep problems (four-point [no problem, mild, moderate, severe] measure) or significantly smaller proportions of infants with mean actigraphic wakes of $\geq$ two per night in the intervention group compared with controls. Infant sleep problems are not confined to night waking per se; they also include parents' interpretations of infant night waking and signaling [23].

The severity measure was taken from the Longitudinal Study of Australian Children - a large nationally representative study using primary caregiver report on a scale about children's sleep (no problem, or mild, moderate, or severe problem) $[6,11,25,26]$. Australian parents' reports of sleep problem severity were robust indicators of frequent night waking [26]. The Ambulatory Monitoring Micromini-motion logger ${ }^{\circ}$ was used in a zero crossing mode [27], with upgraded Action- $\mathrm{W}^{\circ}$ version 2.7 software to collect and analyze actigraphy data [28]. The actigraphs were worn on infants' left ankles for 6 days. The software incorporates Sadeh's algorithm [28] for differentiating sleep and wakes in infants less than one year of age. Most studies employing actigraphy reported using Ambulatory Monitoring actigraphs [29]. Actigraphic data have had high rates of agreement with polysomnography (PSG) recordings [30, 31]. Following downloading, a physician, blinded to group assignment, scored all of the actigraph data. Families also completed an infant sleep diary and a form with settling and rising and actigraph removal and reapplication times to assist with interpretation of the actigraphy data. Sleep diaries have been used in large longitudinal studies to determine children's sleep duration and night waking [32].

Our secondary outcomes were infants' longest sleep time in minutes (actigraphy) and mean wakes (actigraphy and diary) and parents' experiences, using the Multidimensional Assessment of Fatigue Scale [MAF] [33], Center for Epidemiologic Studies Depression Measure [CESD] [34], Pittsburgh Sleep Quality Index [PSQI] [35], and Maternal (parental) Cognitions about Infant Sleep Questionnaire [MCISQ] [36], at six weeks post-teaching session. For psychological measures, higher scores indicate more difficulty. There is support for validity and reliability; instrument testing occurred in the pilot study [14, 15]. For the trial, Cronbach's alphas were: MAF 0.94, 0.95; CESD 0.90, 0.89; PSQI 0.64, 0.53; MCISQ 0.79, 0.84. The MCISQ has not been validated with fathers; however, Morrell's items were developed from therapy vignettes for couples experiencing an infant sleep problem [36] and other studies have used the measure with mothers and fathers $[22,23]$. Our original secondary hypothesis specified significantly improved changes in experimental versus control group parents' experiences; however, we capitalized on data from both parents by conducting a post hoc analysis comparing primary and secondary caregivers separately.

\section{Statistical analyses}

Our sample size was based on detecting an arithmetic difference of $20 \%$ in outcome proportion reporting severe sleep problems between the intervention and control groups [6], using results obtained by Hiscock and colleagues' (2007) who reported $70 \%$ in control group and $50 \%$ in intervention group. That absolute difference required 97 subjects per group to obtain power 
of 0.80 in a two-sided test with type I error rate of 0.05 . Allowing for loss of follow up of up to $20 \%$, our planned sample size was 240 families; we recruited and randomized a total of 235 families. We did not incorporate secondary outcomes in our power calculation. No interim analysis was planned.

The primary analyses were conducted on an intentionto-treat basis considering a two-tailed $\mathrm{p}$-value $\leq 0.05$ as significant and using $\mathrm{R}$ (version 2.13.0). We compared observed proportions of parents reporting severe sleep problems and actigraphic wakes of $\geq 2$ per night between groups using a Fisher's exact test, with adjustment for baseline sleep problem severity using the Mantel-Haenszel test, including corresponding $95 \%$ confidence intervals for differences in proportions or relative risks. Means for continuous outcomes were compared using linear (both fixed and mixed effects) model analyses, with adjustment for baseline measurements. We adjusted our analysis of sleep problem severity for infant gender and feeding status.

Because families were assigned to groups associated with particular health centers and providers we examined health center and provider effects on primary outcomes using mixed effects logistic regression. In addition, we generated multiple imputations for incomplete data using iterative regression imputation [37]. The results reported are based on the available data. Multiple imputation was undertaken to confirm the validity of the available data analysis.

\section{Results}

We screened 386 families for study eligibility (Fig. 1). Sixty-eight infants $(17.6 \%)$ were excluded because they were: outside the age range $(n=28)$, had chronic health problems $(n=2)$, or did not meet the BSP criteria $(n=38)$. Thirty-eight parents $(9.8 \%)$ were excluded because they lived outside the study catchment $(n=10)$, were unavailable for training sessions $(n=5)$, or had diagnoses of depression or sleep apnea $(n=23)$. Twenty-seven families (7\%) refused participation because they regarded data collection as too onerous. Of 253 families (66\%) that agreed to baseline data collection, 18 (7\%) could not be randomized due to infant illness $(n=1)$, family bereavement $(n=1)$, parents separating $(n=1)$, and regarding the study as too onerous $(n=15)$. Two hundred and thirty-five families (462 parents) were randomized to the intervention and control groups. At six weeks, 110 families (206 parents) were in the intervention group and 108 families (204 parents) were in the control group. Loss to follow-up at the six-week outcome collection point was $6 \%$ in the intervention group and $7.4 \%$ in the control group.

At baseline (Table 3), parents had a mean age of 35 years, a mean of 17 years of education, and most had a partner. Most families had one child. Family income
Table 3 Baseline demographic variables for infants and parents

\begin{tabular}{|c|c|c|}
\hline Category & Sleep intervention & Safety control \\
\hline Infants & $n=117$ & $n=118$ \\
\hline Age, mean (SD), mo & $6.7(0.92)$ & $6.8(0.96)$ \\
\hline Male, No. (\%) & $74(64)$ & $57(48)^{* *}$ \\
\hline Breastfed, No. (\%) & $99(85)$ & $113(96)^{* *}$ \\
\hline Parents & $n=229$ & $n=233$ \\
\hline Age, mean (SD), y & $35.5(5.6)$ & $35.4(5.1)$ \\
\hline $\begin{array}{l}\text { Married or in stable } \\
\text { relationship, No. (\%) }\end{array}$ & $110(97)$ & $110(97)$ \\
\hline Number of children, mean (SD) & $1.3(0.7)$ & $1.3(0.7)$ \\
\hline Education, mean (SD), y & $17(2.8)$ & $17(2.8)$ \\
\hline \multicolumn{3}{|l|}{$\begin{array}{l}\text { Family Income, } \\
\text { Canadian dollars, No. (\%) }\end{array}$} \\
\hline$\$ 10,000-29,999$ & $12(6)$ & $8(4)$ \\
\hline$\$ 30,000-59,999$ & $22(11)$ & $42(20)$ \\
\hline$\$ 60,000-\$ 89,999$ & $36(17)$ & $42(20)$ \\
\hline$\$ 90,000-109,000$ & $56(27)$ & $32(15)$ \\
\hline$\geq \$ 110,000$ & $81(39)$ & $91(42)^{\mathrm{a}}$ \\
\hline \multicolumn{3}{|l|}{ Cultural Identity, No. $(\%)^{b}$} \\
\hline Canadian & $111(50)$ & $123(54)$ \\
\hline Chinese & $23(10)$ & $19(8)$ \\
\hline European & $30(14)$ & $25(11)$ \\
\hline South Asian & $21(9)$ & $20(9)$ \\
\hline Other & $38(17)$ & $42(18)$ \\
\hline
\end{tabular}

${ }^{\mathrm{a}}$ Rounding error. ${ }^{\mathrm{b}}$ Parents self-determined cultural identity Note: ${ }^{* *} p<.01$

ranged from $\$ 10,000$ to $\geq \$ 110,000$ per annum, with about $40 \%$ of the sample reporting incomes between $\$ 10,000$ and $\$ 89,999$ CAD per annum. The majority of the sample self-identified as Canadian, with the next largest groups reported as European, Chinese, and South Asian. The groups were similar except there were more male infants and fewer breastfeeding infants in the intervention group compared with the control group. Both parents attended the sleep session in $86 \%$ of families and the safety session in $62 \%$ of families. An average of nine parents per group attended each sleep and safety teaching session. For follow-up telephone calls, $98 \%$ of sleep group and $85 \%$ of safety group families received the first call, $96 \%$ and $80 \%$ received the second call, $94 \%$ and $80 \%$ received the third call, and $86 \%$ and $79 \%$ received the fourth call. The sleep group averaged 3.7 calls per family and the safety group 3.3 calls per family.

\section{Primary outcome}

Incomplete actigraphic data (missing epochs due to signal loss) for a 24-h period were excluded from analysis and occurred similarly across intervention and control 
groups ( $7.6 \%$ and $8.1 \%$ respectively). At six weeks postintervention, 96 actigraphy records were analyzed for each group. Ninety-four control group infants had an average of $\geq 2$ wakes per night compared to 93 intervention group infants, a risk difference of $-0.2 \%$ (95\% CI: $-1.32,0.91)$. At six weeks, $4 \%$ of infants in the intervention group $(n=4)$ compared to $14 \%$ of infants in the control group $(n=15)$ had parental reports of severe sleep problem scores (relative risk of 0.26 [95 \% CI: 0.09, 0.77]); adjusting for baseline scores yielded an estimate of 0.30 (95 \% CI: $0.11,0.84)$ and a risk difference of $-10 \%$ (95\% CI: -16.8 , -2.2) (Table 4). No estimates were substantially affected by adjustment for baseline characteristics. Adjusting for infant gender and feeding status did not alter the sleep problem severity results. There was no indication of pertinent variation between centers or providers.

\section{Secondary outcomes}

At six weeks, there was no difference between the intervention and control groups for mean change in actigraphic wakes or long wake episodes adjusted for baseline; however, there was a significant increase in the intervention compared to control infants' longest sleep time (Table 4). Diary data were provided for 106 intervention and 106 control infants. Parents recorded significantly fewer wakes for intervention infants than control infants; $31.1 \%$ of intervention infants compared to $60.4 \%$ control infants had $\geq 2$ night wakes (Table 4).

After adjusting for baseline, change in parents' psychological measures indicated significant improvements for the intervention compared to the control group (Table 5). Intervention group parents' fatigue, sleep quality, and depressed mood improved significantly compared to control group parents. As indicated, we conducted a post hoc analysis to compare changes in primary and secondary caregivers' psychological variables between groups, after adjusting for baseline. For the intervention group, both primary and secondary caregivers' sleep quality and fatigue improved significantly compared to the control group (Table 6). Depression improved for the primary caregivers in the intervention group compared to the control group but not for secondary caregivers.

When we examined parental cognitions about sleep, after controlling for baseline, there was a significant improvement in all areas of cognition, except for sleep safety, on comparing intervention parents with controls (Table 5). In the post hoc analysis we analyzed data for primary and secondary caregivers separately. For both primary and secondary caregivers the intervention groups' doubts about managing infant sleep, comfort managing sleep and feeding, and comfort setting limits around infant sleep improved significantly compared to the control group (Table 6). Primary caregivers' cognitions of anger about infant sleep but not secondary caregivers' cognitions improved significantly for the intervention group compared to the control group. There were no significant differences in intervention group primary or secondary care providers' concerns about sleep safety compared to the control group.

\section{Discussion}

Given the frequency of BSPs in infancy and their negative long-term effects on parents and children [1-9] brief and effective interventions to manage BSPs are important. Ninety percent of American school-aged children have received less than the recommended hours of sleep [38]. Finding ways to reach parents and assist them to recognize BSP as amenable to change early in children's development can potentially improve parents' knowledge about sleep, factors influencing sleep, and approaches to managing children's sleep. This is the first trial of the efficacy of a cognitive-behavioral group intervention (CBGI) for parents with infants from 6- to 8-months of age with BSPs. While the control group

Table 4 Infant sleep characteristics at baseline and 6 weeks

\begin{tabular}{|c|c|c|c|c|c|c|c|}
\hline & \multicolumn{2}{|c|}{ Sleep intervention } & \multicolumn{2}{|c|}{ Safety control } & \multirow{2}{*}{$\begin{array}{l}\text { Adjusted difference } \\
\text { at outcome }\end{array}$} & \multirow{2}{*}{$\begin{array}{l}95 \% \text { confidence } \\
\text { interval }\end{array}$} & \multirow[t]{2}{*}{$P$-value } \\
\hline & Baseline & 6 Week & Baseline & 6 Week & & & \\
\hline Actigraphy & $n=113$ & $n=96$ & $n=109$ & $n=96$ & & & \\
\hline Night wake episodes & $8.2(3.8)$ & $7.9(5.4)$ & $8.8(3.4)$ & $7.7(4.3)$ & -0.2 & -1.32 to 0.91 & 0.72 \\
\hline Long wake episodes & $4(1.5)$ & $3.2(1.6)$ & $4.2(1.4)$ & $3.2(1.2)$ & 0.02 & -0.35 to 0.4 & 0.91 \\
\hline Longest sleep period & $164(46.2)$ & $204.4(87.5)$ & $168(53.2)$ & $188.1(50.2)$ & 20.02 & 0.48 to 39.56 & 0.05 \\
\hline Sleep diary & $n=114$ & $n=106$ & $n=116$ & $n=106$ & & & \\
\hline Night wake episodes & $3.1(1.2)$ & $1.7(1)$ & $3.1(1.2)$ & $2.2(1.1)$ & -0.45 & -0.7 to -0.19 & $<.001$ \\
\hline $\begin{array}{l}\% \text { infants with sleep problem } \\
\text { (average }=2 \text { wakes per night) }\end{array}$ & $93(81.6 \%)$ & $33(31.1 \%)$ & $96(82.8 \%)$ & $64(60.4 \%)$ & $-29.9 \%$ & -43.63 to -16.22 & $<.001$ \\
\hline Parent report & $n=117$ & $n=108$ & $n=118$ & $n=107$ & & & \\
\hline$\%$ of infants with severe night waking & $32(14 \%)$ & $4(4 \%)$ & $44(18 \%)$ & $15(14 \%)$ & $-10 \%$ & -16.8 to -2.2 & 0.01 \\
\hline
\end{tabular}

Descriptive statistics are reported as Mean (SD) or $\mathrm{n}(\%)$ 
Table 5 Comparison of intervention and control group parents for psychological variables

\begin{tabular}{|c|c|c|c|c|c|}
\hline & Baseline mean (SD) (n) & $\begin{array}{l}6 \text { week follow-up } \\
\text { mean (SD) (n) }\end{array}$ & $\begin{array}{l}\text { Baseline adjusted } \\
\text { difference }\end{array}$ & $\begin{array}{l}95 \% \text { confidence } \\
\text { interval }\end{array}$ & $P$-value \\
\hline \multicolumn{6}{|l|}{ Fatigue $\mathrm{MAF}^{\mathrm{a}}$} \\
\hline Sleep intervention & $26.8(9.2)(n=206)$ & $18.7(8.1)(n=206)$ & -3.7 & -5.74 to -1.68 & 0.001 \\
\hline Safety control & $27.1(8.6)(n=204)$ & $22.3(9.2)(n=204)$ & & & \\
\hline \multicolumn{6}{|l|}{ Depression CES-D ${ }^{b}$} \\
\hline Sleep intervention & $13.8(9)(n=206)$ & $9.4(7.7)(n=206)$ & -2 & -3.7 to -0.4 & 0.02 \\
\hline Safety control & $15.4(10.2)(n=205)$ & $12(9)(n=205)$ & & & \\
\hline \multicolumn{6}{|l|}{ Sleep quality PSQI ${ }^{c}$} \\
\hline Sleep intervention & $8.1(3.6)(n=206)$ & $5.7(3)(n=206)$ & -0.88 & -1.5 to -0.2 & 0.009 \\
\hline Safety control & $8.3(3.4)(n=201)$ & $6.5(3.3)(n=202)$ & & & \\
\hline \multicolumn{6}{|l|}{ Cognitions MCISQ } \\
\hline Sleep intervention & $n=223$ & $n=205$ & & & \\
\hline Safety control & $n=230$ & $n=205$ & & & \\
\hline \multicolumn{6}{|l|}{ Sleep doubts ${ }^{e}$} \\
\hline Sleep intervention & $7.2(4.1)$ & $4.3(3.6)$ & -1.3 & -2.0 to -0.6 & $<.001$ \\
\hline Safety control & $6.9(4.2)$ & $5.5(4)$ & & & \\
\hline \multicolumn{6}{|l|}{ Sleep anger ${ }^{f}$} \\
\hline Sleep intervention & $6.8(3.4)$ & $5.2(3.1)$ & -1.1 & -1.8 to -0.4 & 0.003 \\
\hline Safety control & $7.3(4)$ & $6.5(3.8)$ & & & \\
\hline \multicolumn{6}{|l|}{ Sleep and feeding ${ }^{g}$} \\
\hline Sleep intervention & $7.3(3.6)$ & $3.9(3.4)$ & -1.4 & -2.1 to -0.7 & $<.001$ \\
\hline Safety control & $6.9(3.6)$ & $5.2(3.3)$ & & & \\
\hline \multicolumn{6}{|l|}{ Setting sleep limits ${ }^{h}$} \\
\hline Sleep intervention & $14.9(4.9)$ & $10.1(4.8)$ & -2.48 & -3.5 to -1.5 & $<.001$ \\
\hline Safety control & $14.9(4.9)$ & $12.4(5.2)$ & & & \\
\hline \multicolumn{6}{|l|}{ Sleep safety ${ }^{i}$} \\
\hline Sleep intervention & $2.9(2.5)$ & $1.9(2)$ & -0.3 & 0.7 to 0.1 & 0.12 \\
\hline Safety control & $2.7(2.4)$ & $2.2(2.3)$ & & & \\
\hline
\end{tabular}

${ }^{a}$ Multidimensional Assessment of Fatigue Scale (global score range 1-50; higher scores indicate greater fatigue)

${ }^{\mathrm{b} C}$ Centre for Epidemiologic Studies Depression Measure (score range 0-60, higher scores indicate worse depression)

${ }^{c}$ Pittsburgh Sleep Quality Index (global score range 0-21; higher scores indicate worse sleep quality)

${ }^{d}$ Maternal Cognitions about Infant Sleep Questionnaire (higher scores indicate more parent difficulty)

Subscale score range for: ${ }^{\mathrm{e}}$ Doubts about managing sleep $=0-25,{ }^{\mathrm{f}}$ Anger about infant sleep $=0-25$

${ }^{9}$ Managing infant sleep and feeding $=0-15$, h Setting i nfant sleep limits $=0-25$, Infant sleep safety $=0-10$. The means were adjusted for baseline

also improved over time, our principal findings (adjusted for baseline) indicated a significant improvement in parents' perceptions of the severity of the infant sleep problem, reduction in numbers of night wakes by sleep diary, increase in length of longest night sleep by actigraphy, and improvement in parents' cognitions about infant sleep, fatigue, sleep quality, and depression in the intervention group compared to the control group.

The results, including no significant reduction in night waking by actigraphy, support the efficacy of our intervention and our goal to assist parents to accept normal infant arousal behavior by understanding the effects of self-soothing. The diary data demonstrated that a clinically significant proportion of infants in the intervention group managed to return to sleep following typical night arousals without signaling their parents. Behavioral interventions are intended to assist infants to selfsoothe back to sleep rather than to prevent night waking. In the intervention content we emphasized links between parental responses to infants' crying and signaling and infants' failure to learn to self-soothe to return to sleep following typical night waking. Parental responses to infant signaling can interfere with self-soothing and extend the duration of infants' night waking [39]. 
Table 6 Comparison of intervention and control group by caregiver on psychological variables at 6 weeks

\begin{tabular}{|c|c|c|c|c|c|c|c|}
\hline \multirow[t]{2}{*}{ Variable \& caregivers } & \multicolumn{2}{|c|}{ Sleep intervention } & \multicolumn{2}{|c|}{ Safety control } & \multirow[t]{2}{*}{ Baseline adjusted difference } & \multirow[t]{2}{*}{$95 \%$ confidence interval } & \multirow[t]{2}{*}{$P$ value } \\
\hline & Mean (SD) & $n$ & Mean (SD) & $n$ & & & \\
\hline \multicolumn{8}{|l|}{ Fatigue $\mathrm{MAF}^{\mathrm{a}}$} \\
\hline Primary caregiver & $19.3(8.1)$ & 108 & $23.5(9.2)$ & 105 & -4.2 & -6.45 to -1.96 & $<.001$ \\
\hline Secondary caregiver & $18.1(8.1)$ & 98 & $21.1(9)$ & 99 & -2.7 & -4.90 to -0.50 & .02 \\
\hline \multicolumn{8}{|l|}{ Depression CES-D ${ }^{b}$} \\
\hline Primary caregiver & $9.1(7.9)$ & 108 & $12.5(8.4)$ & 106 & -2.87 & -4.81 to -0.93 & .004 \\
\hline Secondary caregiver & $9.7(7.5)$ & 98 & $11.5(9.7)$ & 100 & -0.77 & -2.89. to 1.36 & .48 \\
\hline \multicolumn{8}{|l|}{ Sleep quality PSQI ${ }^{c}$} \\
\hline Primary caregiver & $6.2(3.1)$ & 108 & $7.1(3.4)$ & 107 & -0.88 & -1.70 to -0.06 & .04 \\
\hline Secondary caregiver & $5.1(2.8)$ & 98 & $5.9(3.1)$ & 95 & -0.72 & -1.45 to 0.01 & .05 \\
\hline \multicolumn{8}{|l|}{ Cognitions MCISQ ${ }^{d}$} \\
\hline \multicolumn{8}{|l|}{ Sleep doubts ${ }^{\mathrm{e}}$} \\
\hline Primary caregiver & $4.6(3.5)$ & 108 & $5.9(4)$ & 107 & -1.56 & -2.43 to -0.68 & $<.001$ \\
\hline Secondary caregiver & $3.9(3.7)$ & 97 & $5.1(4.1)$ & 98 & -1.26 & -2.14 to -0.39 & .005 \\
\hline \multicolumn{8}{|l|}{ Sleep anger ${ }^{f}$} \\
\hline Primary caregiver & $5(3.3)$ & 108 & $6.6(4.2)$ & 107 & -1.37 & 2.25 to -0.50 & .002 \\
\hline Secondary caregiver & $5.3(2.9)$ & 97 & $6.3(3.3)$ & 98 & -0.75 & 1.54 to 0.31 & .06 \\
\hline \multicolumn{8}{|l|}{ Sleep and feeding ${ }^{g}$} \\
\hline Primary caregiver & $4.5(3.6)$ & 108 & $6(3.3)$ & 107 & -1.59 & 2.41 to -0.77 & $<.001$ \\
\hline Secondary caregiver & $3.2(3.2)$ & 97 & $4.4(3.2)$ & 98 & -1.4 & 2.19 to -0.61 & $<.001$ \\
\hline \multicolumn{8}{|l|}{ Setting sleep limits ${ }^{\mathrm{h}}$} \\
\hline Primary caregiver & $10.8(4.8)$ & 108 & $13.5(5.2)$ & 107 & -2.63 & -3.80 to -1.47 & $<.001$ \\
\hline Secondary caregiver & $9.2(4.8)$ & 97 & $11.1(4.9)$ & 98 & -2 & -3.12 to -0.88 & $<.001$ \\
\hline \multicolumn{8}{|l|}{ Sleep safety ${ }^{i}$} \\
\hline Primary caregiver & $2.2(2)$ & 108 & $2.5(2.2)$ & 107 & -0.42 & 0.91 to 0.07 & .09 \\
\hline Secondary caregiver & $1.7(2)$ & 97 & $2(2.3)$ & 98 & -0.3 & 0.80 to 0.20 & .25 \\
\hline
\end{tabular}

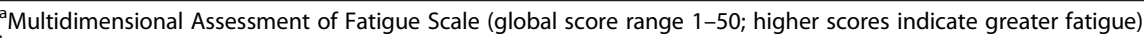

${ }^{b}$ Centre for Epidemiologic Studies Depression Measure (score range 0-60, higher scores indicate worse depression)

'Pittsburgh Sleep Quality Index (global score range 0-21; higher scores indicate worse sleep quality)

${ }^{\mathrm{d}}$ Maternal Cognitions about Infant Sleep Questionnaire (higher scores indicate more parent difficulty)

Subscale score range for: ${ }^{\mathrm{e}}$ Doubts about managing sleep $=0-25,{ }^{\mathrm{f}}$ Anger about infant sleep $=0-25$

${ }^{9}$ Managing infant sleep and feeding $=0-15$, hSetting infant sleep limits $=0-25$, 'Infant sleep safety $=0-10$. The means were adjusted for baseline

Adjusting for baseline, there was not a significant improvement in actigraphy night waking in the intervention group compared with the controls, even when we compared the groups on long wakes. Our results fit with emerging research suggesting that actigraphs lack specificity to detect wakes in infants [29]. Actigraphy data have shown low specificity for children's wakes but high intraclass correlations with polysomnography for sleep duration [40].

The differences between primary and secondary caregivers' improvement in depression and sleep anger fit with findings of other studies. For example, Hiscock and Wake reported that mothers who regarded their infants' sleep as a problem were more likely to have depression and depression scores increased with sleep problem severity [41]. Another study reported significant correlations between maternal sleep cognitions and depression scores, with mothers of children with sleep problems scoring significantly higher on anger about sleep than mothers of control children [42]. In our study, primary caregivers were the parents engaging with settling infants to sleep, night waking, and the intervention.

\section{Strengths and limitations}

The trial responded to a number of criticisms of sleep interventions [13] by offering a small group format, a relatively brief intervention, a combination of objective and subjective sleep measures, and a standardized definition of a behavioral sleep problem [19]. The trial was preceded by a pilot study $[14,15]$ and incorporated a standardized intervention through formal training of nurses, scripted interventions, systematic review of intervention 
fidelity, and less than $10 \%$ attrition at primary outcome. In the pilot study $[14,15]$, the principal investigator delivered all of the sleep interventions for the seven groups of parents and provided all of the telephone support thereby ensuring fidelity was maintained. We created similar exposure to attention for the sleep and safety groups and blinded our participants to our hypotheses [43]. We incorporated secondary care providers (fathers) in our trial in contrast to previous foci on mothers alone [21], given evidence both parents influence children's sleep patterns [22].

Exclusion of parents who did not read or speak English and research participant characteristics (older, well-educated and high income) limits the generalizability of results. It is interesting that our sample is relatively representative of the population being served. About $40 \%$ of our sample reported average family incomes of between $\$ 10,000$ and $\$ 89,999$ CAD; these family income levels are relatively common in the city where the study was conducted. In 2011, the mean and median household incomes for Metro Vancouver were $\$ 83,666 \mathrm{CAD}$ and $\$ 63,347$ respectively [44] and median couple income in Vancouver in 2012 was reported as $\$ 76,690$ CAD [45]. In Vancouver in 2011, $60 \%$ of adults reported university education or college diplomas [46].

Lack of blinding for parent participants had the potential to bias the study results. We asked about other resources parents accessed but did not place limits on parents' access to other forms of help, such as sleep consultants. We did not control for parents' access to other services because we intended the trial to resemble public health nurses' practice where parents would have unlimited access to other resources. The lengthy recruitment period increased the possibility that control group parents were contaminated by conversing with parents, who received the trial intervention. Both lack of parental blinding and contamination of the control group could potentially have contributed to underestimating the effect size of the outcome. Some parents might prefer one-to-one rather than group formats to assist with problems.

We did not compare intervention and control groups for sleep-onset difficulties in our study for several reasons. At baseline, parents were often rocking or feeding their infants to sleep. Thus, the actigraphic mean for sleep onset latency at baseline was $0.58 \mathrm{~min}$. Parents often reported settling their infants after they specified sleep onset on written diaries. In other words, infants were asleep when parents placed them in their cribs. Infants are unable to indicate when they try to initiate sleep so we suggest that the standard definition of sleep latency does not apply to this developmental group.

We were not surprised that, despite significant differences between groups on infant gender and breastfeeding status at baseline (Table 3), adjusting for their status did not affect our results for sleep problem severity. In large multinational studies, neither gender nor breastfeeding status has influenced night waking [47, 48]. It has been breastfeeding to sleep that has been associated with sleep problems [48] and our intervention recommended that parents refrain from feeding infants to sleep.

The availability of public health nurses trained in behavioral sleep interventions creates potential for nurses to offer interventions through contact with families attending group postnatal drop-ins. Not only can situating a short-term group intervention in public health units overcome barriers to families receiving help for common infant BSPs $[49,50]$ but also being exposed to other families experiencing an infant BSP decreases families' sense of isolation and helps them regard their infants' problems as common and amenable to change [16]. Contacting families by telephone for follow-up could be factored into public health nurses' daily workload. Sleep consultants in the area routinely charge families about $\$ 250$ to $\$ 450$ per consultation, thus potentially limiting families' access to such services. Parents' changes in cognitions, observed in our study, suggest that their thinking changed when provided with evidence-based information about infant sleep and strategies to reduce sleep problems by skilled practitioners. Future studies could incorporate video surveillance of infant sleep, a more valid way of identifying insomnias [51], indicators of self-soothing, and attachment measures to provide evidence about effects of interventions on infants.

\section{Conclusions}

Compared to parents in a control group, parents exposed to a CBGI experienced significantly improved perceptions of infant sleep, sleep cognitions, mood, sleep quality, and fatigue, but not number of wakes measured using actigraphy.

\section{Abbreviations}

BSP: Behavioral sleep problem; CBGI: Cognitive-behavioral group intervention; CESD: Center for Epidemiologic Studies Depression Measure; MAF: Multidimensional Assessment of Fatigue Scale; MCISQ: Maternal (parental) Cognitions about Infant Sleep Questionnaire; PSQI: Pittsburgh Sleep Quality Index.

\section{Competing interests}

The authors declare that they have no competing interests.

\section{Authors' contributions}

$\mathrm{WH}$ conceptualized and designed the trial, obtained funding, directed implementation, participated in data analysis and interpretation, wrote the draft manuscript, and is guarantor. EH, JPC, and AG assisted in all trial activities, including design, funding, implementation, data interpretation, and manuscript preparation. RS conducted all of the actigraphy analysis and assisted with manuscript preparation. RFB assisted in design, funding, data analysis and interpretation, and manuscript preparation. RB, KT, LT, and JW participated in trial design, including the intervention and manuscript preparation. KG assisted in all trial implementation procedures including participant recruitment, overseeing implementation and data collection procedures, budget management, managing the database, and manuscript preparation. Ol assisted in trial funding and was available for clinical consultation during implementation. All authors read and approved the final manuscript. 


\section{Author's information}

Over 9 years, WH has provided voluntary sleep consultations to over 1000 families with children with behavioral sleep problems, as well as sessions for foster parents in a community health program. The demand, without any form of advertising, is an indicator of the number of families unable to access assistance with children's sleep problems. Joanne Wooldridge is the Regional Leader for Early Child Development.

\section{Acknowledgements}

We acknowledge the families who participated in the study and shared their experiences with us. This work was funded by a Canadian Institutes of Health Research grant (no MCT - 94836) awarded to Dr. Hall. The researchers conducted the trial and analyzed the data with complete independence from the Canadian Institutes of Health Research.

\section{Funding}

Canadian Institutes of Health Research grant (no MCT - 94836).

\section{Author details}

'University of British Columbia School of Nursing, T 201, 2211 Wesbrook Mall, Vancouver, BC V6T 2B5, Canada. ${ }^{2}$ Midwifery Education Program, McMaster University, Michael G DeGroote Centre for Learning \& Discovery, Room 2210, 1200 Main Street West, Hamilton, ON L8N 3Z5, Canada. ${ }^{3}$ Department of Statistics, University of British Columbia/Child and Family Research Institute, ESB 3146, 2207 Main Mall, Vancouver, BC V6T 1Z4, Canada. ${ }^{4}$ Child and Family Research Institute, University of British Columbia, Clinical Support Building, Room V3-320, 948 West 28th Avenue, Vancouver, BC V6H 3N1, Canada. ${ }^{5}$ University of British Columbia School of Nursing, Vancouver, BC, Canada. EUniversity of British Columbia Faculty of Medicine, 2329 West Mall, Vancouver, BC V6T 1Z4, Canada. 'British Columbia Children's Hospital, Division of Developmental Pediatrics, 3644 Slocan Street, Vancouver, BC V5M 3E8, Canada. ${ }^{8}$ Department of Clinical Epidemiology and Biostatistics, Faculty of Health Sciences, McMaster University, 1280 Main Street West, CRL-208, Hamilton, ON L8S 4K1, Canada. ${ }^{9}$ Pacific Spirit Community Health Centre, Vancouver Coastal Health, 2110 43rd Avenue West, Vancouver, BC V6M 2E1, Canada. ${ }^{10}$ South Community Health Centre, Vancouver Coastal Health, 6405 Knight Street, Vancouver, BC V5P 2V9, Canada. ${ }^{11}$ South Community Health Centre, Vancouver Community, Vancouver Coastal Health, 6405 Knight Street, Vancouver, BC V5P 2V9, Canada. ${ }^{12}$ Early Childhood Development at Vancouver Coastal Health, Vancouver Coastal Health, 11th floor, 601 West Broadway, Vancouver, BC V5Z 4C2, Canada.

Received: 10 June 2015 Accepted: 22 October 2015

Published online: 13 November 2015

\section{References}

1. Touchette E, Petit D, Pacquet J, Boivin M, Japel C, Tremblay RE, et al. Factors associated with fragmented sleep at night across early childhood. Arch Pediatr Adolesc Med. 2005;159:242-9.

2. Palmstierna P, Sepa A, Ludvigsson J. Parent perceptions of child sleep: a study of 10,000 Swedish children. Acta Paediatr. 2008;97:1631-9. doi:10.1111/j.1651-2227.2008.00967.x.

3. Spruyt K, Aitken RJ, So K, Charlton M, Adamson TM, Horne RSC. Relationship between sleep/wake patterns, temperament, and overall development in term infants over the first year of life. Early Hum Dev. 2007:84:289-96. doi:10.1016/j.earlhumdev.2007.07.002.

4. Lucas-Thompson R, Goldberg WA, Germo GR, Davis EP, Sandman CA. Sleep arrangements and night waking at 6 and 12 months in relation to infants' stress-induced cortisol responses. Infant Child Dev. 2009;18:521-44. doi:10.1002/icd.636.

5. Hall WA, Zubrick SR, Silburn SV, Parsons DE, Kurinczuk JJ. A model for predicting behavioral sleep problems in a random sample of Australian pre-schoolers. Infant Child Dev. 2007;16:509-23. doi:10.1002/icd.527.

6. Hiscock H, Bayer J, Gold L, Hampton A, Ukoumunne OC, Wake M. Improving infant sleep and maternal mental health: a cluster randomized trial. Arch Dis Child. 2007;92:952-8. doi:10.1136/adc.2006.099812.

7. Reid GJ, Hong RY, Wade TJ. The relation between common sleep problems and emotional and behavioral problems among 2- and 3-year-olds in the context of known risk factors for psychopathology. J Sleep Res. 2009;18:49-59. doi:10.1111/j.1365-2869.2008.00692.x.
8. Touchette E, Petit D, Séguin JR, Boivin M, Tremblay RE, Montplaisir JY. Associations between sleep duration patterns and behavioral/cognitive functioning at school entry. Sleep. 2007;30:1213-9.

9. Touchette E, Petit D, Séguin JR, Boivin M, Falissard B, Tremblay RE, et al. Short night-time sleep-duration and hyperactivity trajectories in early childhood. Pediatrics. 2009;124:e985-93.

10. Dagher RK, McGovern PM, Dowd BE, Lundberg U. Postpartum depression symptoms and the combined load of paid and unpaid work: a longitudinal analysis. Int Arch Occup Environ Health. 2011;84:735-43. doi:10.1007/s00420-011-0626-7.

11. Martin J, Hiscock H, Hardy P, Davey B, Wake M. Adverse associations of infant and child sleep problems and parent health: an Australian population study. Pediatrics. 2007;119:947-55.

12. Thunström M. Severe sleep problems among infants: family and infant characteristics. Ambulatory Child Health. 1999;5:27-41.

13. Mindell JA, Kuhn B, Lewin DS, Meltzer $L$, Sadeh A. Behavioral treatment of bedtime problems and night wakings in infants and young children - an American Academy of Sleep Medicine review. Sleep. 2006;29:1263-76.

14. Hall WA, Saunders RA, Clauson M, Carty EM, Janssen PA. Effects of an intervention aimed at reducing night waking and signaling in 6- to 12-month-old infants. Behav Sleep Med. 2006:4:242-61. doi:10.1207/s15402010bsm0404_4.

15. Hall WA, Clauson M, Carty EM, Janssen PA, Saunders RA. Effects on parents of an intervention to resolve infant behavioural sleep problems. Pediatr Nurs. 2006;32:243-54.

16. Tse $L$, Hall WA. A qualitative study of parents' perceptions of a behavioural sleep intervention. Child Care Health Dev. 2007;34:162-72. doi:10.1111/j.1365-2214.2007.00769.x.

17. Canadian Public Health Association: Public Health Community Health Nursing Practice in Canada: Roles and Activities (4 ${ }^{\text {th }}$ edition). 2010. http://cpha.ca/uploads/pubs/3-1bk04214.pdf. Accessed 27 Mar 2015.

18. Vancouver Coastal Health: Vancouver Coastal Health Parent and Infant Drop-in Groups (2015). http://www.vch.ca/your-health/infants,-children\&-youth/parent-and-child-drop-in-groups/. Accessed 27 Mar 2015.

19. American Academy of Sleep Medicine. International classification of sleep disorders, revised diagnostic and coding manual. Westchester, IL: American Academy of Sleep Medicine; 2001.

20. Henderson JMT, France KG, Blampied NM. The consolidation of infants nocturnal sleep across the first year of life. Sleep Med Rev. 2011;15:211-20. doi:10.1016/j.smrv.2010.08.003.

21. Sadeh A, Tikotzky L, Scher A. Parenting and infant sleep. Sleep Med Rev. 2010;14:89-96.

22. Sadeh A, Flint-Ofir E, Tirosh T, Tikotzy L. Infant sleep and parental sleep-related cognitions. J Fam Psychol. 2007;21:74-87.

23. Tikotzky L, Shaashua L. Infant sleep and early parental sleep-related cognitions predict sleep in pre-school children. Sleep Med. 2012;13:185-92 doi:10.1016/j.sleep.2011.07.013.

24. Hiscock H, Wake M. Randomized controlled trial of a behavioural sleep intervention to improve infant sleep and maternal mood. Br Med J. 2002;324:1062-5. doi:10.1136/bmj.324.7345.1062.

25. Hiscock H, Scalzo K, Canterford L, Wake M. Sleep duration and body mass index in 0-7-year olds. Arch Dis Child. 2011;96:735-9. doi:10.1136/adc.2010.204925.

26. Quach J, Hiscock H, Canterford L, Wake M. Outcomes of child sleep problems over the school-transition period: Australian population longitudinal study. Pediatrics. 2009;123:1287-92.

27. Ambulatory Monitoring. The MicroMini Motionlogger Actigraph and Family of Single Sense Recorders: User's Manual to Accompany Act Millennium Version 3.5 and higher. Ardsley, NY: Ambulatory Monitoring; 2002.

28. Monitoring A. Action-W, user's guide, version 2.4. Ardsley, NY: Ambulatory Monitoring; 2002.

29. Meltzer LJ, Montgomery-Downs HE, Insana SP, Walsh CM. Use of actigraphy for assessment in pediatric sleep research. Sleep Med Rev. 2012;16:463-75. doi:10.1016/j.smrv.2011.10.002.

30. So K, Buckley P, Adamson TM, Horne RC. Actigraphy correctly predicts sleep behaviour in infants who are younger than 6 months when compared with polysomnograpy. Pediatr Res. 2005;58:761-5. doi:10.1203/01.PDR.0000180568.97221.56.

31. Sadeh A, Lavie P, Scher A, Tirosh E, Epstein R. Actigraphic home-monitoring sleep-disturbed and control infants and young children: a new method for pediatric assessment of sleep-wake patterns. Pediatrics. 1991;87:494-9. 
32. Price AMH, Brown JE, Bittman M, Wake M, Quach J, Hiscock H. Children's sleep patterns from 0 to 9 years: Australian population longitudinal study. Arch Dis Child. 2014;99:119-25. doi:10.1136/archdischild-2013-304150.

33. Belza BL, Curtis JH, Yelin EH, Epstein WV, Gillis CL. Correlates of fatigue in older adults with rheumatoid arthritis. Nurs Res. 1993;42:93-9. doi:10.1097/00006199-199303000-00006.

34. Radloff LS. The CES-D: a self-report depression scale for research in the general population. Appl Psych Meas. 1977;1:385-401. doi:10.1177/014662167700100306.

35. Buysse DJ, Reynolds CF, Monk TH, Berman SR, Kupfer DJ. The Pittsburgh Sleep Quality Index: A new instrument for psychiatric practice and research. Psychiat Res. 1989;28:193-213. doi:10.1016/0165-1781(89)90047-4.

36. Morrell JMB. The role of maternal cognitions in infant sleep problems as assessed by a new instrument, the Maternal Cognitions about Infant Sleep Questionnaire. J Child Psychol Psychiatry. 1999;40:247-58.

37. Su Y, Gelman A, Hill J, Yajima M. Multiple imputation with diagnostics (mi) in R: Opening windows into the black box. J Stat SoftW. 2011;45:1-31.

38. Buxton OF, Chang A, Spilsbury JC, Bos T, Emsellem H, Knutson KL. Sleep in the modern family: protective routines for child and adolescent sleep. Sleep Health. 2015;1:15-27. doi:10.1016/j.sleh.2014.12.002.

39. France KG, Blampied NM. Infant sleep disturbance: description of a problem behavior process. Sleep Med Rev. 1999;3:265-80.

40. Bélanger M, Bernier A, Paquet J, Simard V, Carrier J. Validating actigraphy as a measure of sleep for preschool children. J Clinical Sleep Med. 2013;9:701-6. doi:10.5664/jcsm.2844.

41. Hiscock H, Wake M. Infant Sleep Problems and Postnatal Depression: A Community-Based Study. Pediatrics. 2001;107:1317-22. doi:10.1542/peds.107.6.1317.

42. Golik T, Avni H, Nehama H, Greenfield M, Sivan Y, Tauman R. Maternal cognitions and depression in childhood behavioral insomnia and feeding disturbances. Sleep Med. 2013;14:261-4. doi:10.1016/j.sleep.2012.10.025.

43. Boutron I, Guittet L, Estellat C, Moher D, Hróbjartsson A, Ravaud P. Reporting methods of blinding in randomized trials assessing nonpharmacological treatments. PLoS Med. 2007;4:e61. doi:10.1371/journal.pmed.0040061.

44. Metro Vancouver.org [Internet]. Household income - Average income and median income $\$, 1991,1996,2001,2006$, and 2011. [published 18 Nov 2013]. http://www.metrovancouver.org/services/regionalplanning/ PlanningPublications/AverageandMedianHouseholdlncomeby Municipality.pdf\#search=average\%20and\%20median\%20household\%20 income\%20by\%20municipality Accessed 28 Mar 2015.

45. Statistics Canada [Internet]. Median total income by family type by census metropolitan area (Couple families). Statistics Canada website. [published 23 July 2014]: http://www.statcan.gc.ca/tables-tab/eaux/sum-som/ 101/cst01/famil107a-eng.htm Accessed 28 Mar 2015.

46. Statistics Canada [Internet]. Proportion of the population aged 25 to 64 by highest level of educational attainment, six largest metropolitan areas, 2011. [published 17 June 2013]: http://www12.statcan.gc.ca/nhs-enm/2011/as-sa/ 99-012-x/2011001/c-g/c-g04-eng.cfm Accessed 28 Mar 2015.

47. Sadeh A, Mindell JA, Luedtke K, Wiegand B. Sleep and sleep ecology in the first 3 years: a web-based study. J Sleep Res. 2009;18:60-73. doi:10.1111/j.1365-2869.2008.00699.x.

48. Ramamurthy MB, Sekartini R, Ruangdaranon N, Huynh DHT, Sadeh A, Mindell J. Effect of current breastfeeding on sleep patterns in infants from the Asia-Pacific region. J Paediatr Child H. 2012;48:669-74.

49. Gruber R, Cassoff J, Knäuper B. Sleep health education in pediatric community settings: rationale and practical suggestions for incorporating healthy sleep education into pediatric practice. Pediatr Clin North Am. 2011;58:735-54. doi:10.1016/j.pcl.2011.03.006.

50. Stojanovski SD, Rasu RS, Balkrishnan R, Nahata MC. Trends in medication prescribing for pediatric sleep difficulties in US outpatient settings. Sleep 2007;30:1013-7.

51. Sitnick SL, Goodlin-Jones BL, Anders TF. The use of actigraphy to study sleep disorders in preschoolers: Some concerns about detection of nighttime awakenings. Sleep. 2008;31:395-401.

\section{Submit your next manuscript to BioMed Central and take full advantage of:}

- Convenient online submission

- Thorough peer review

- No space constraints or color figure charges

- Immediate publication on acceptance

- Inclusion in PubMed, CAS, Scopus and Google Scholar

- Research which is freely available for redistribution

Submit your manuscript at www.biomedcentral.com/submit 